\title{
Barrios intervenidos artísticamente durante el último franquismo ${ }^{1}$
}

\author{
ISABEL GARCÍA GARCÍA \\ Profesora Titular de Historia del Arte. Departamento de Arte III (Contemporáneo) \\ Universidad Complutense de Madrid \\ isabelgarcia33@hotmail.com
}

\begin{abstract}
Resumen
A mediados de la década de los '70 tiene lugar una protesta de carácter artístico en el Barrio de Portugalete como consecuencia del Plan de Ordenación de la Ciudad Lineal. En tres días se realizaron más de cincuenta murales reivindicativos de artistas tan conocidos como Juan Genovés, Lucio Muñoz, Arcadio Blasco, José Duarte, José Vento, Aragonés, Alcaín, Ángel Orcajo, Zamorano, etc. Para algunos fue una manera de llamar la atención sobre sus problemas, para otros, un modelo de arte comunitario, de arte popular, de arte mural pictórico-poético, de arte vivo, arte en la calle, de museo al aire libre y tantos otros calificativos que recibió en su momento.
\end{abstract}

Palabras clave: arte en la calle; Madrid; APSA; Juan Genovés; Lucio Muñoz; Arcadio Blasco; José Duarte; José Vento; Aragonés; Alcaín; Ángel Orcajo; Zamorano; Agustín Ibarrola; Guernica; Picasso; Prada Poole.

1 Este texto se enmarca dentro de los proyectos de investigación Tras la República: redes y caminos de ida y vuelta en el arte español desde 1931. P.N. de I+D+i, Ref:HAR201125864 y Arquitectura, urbanismo y representación en la construcción de la imagen de los barrios artísticos. P.N. de I+D+i, Ref. HAR2012-38899-C02-02. 


\title{
Artistically transformed neighbourhoods in the late 1970s
}

\begin{abstract}
It took place, in the mid 1970s, an artistic public protest in the Barrio de Portugalete (Madrid), as a consequence of the Plan de Ordenación de la Ciudad Lineal. More tan fifty claiming murals were produced then, from well-known artists like Juan Genovés, Lucio Muñoz, Arcadio Blasco, José Duarte, José Vento, Aragonés, Alcaín, Ángel Orcajo, Zamorano, and so on. It was, for some of them, a way of drawing the attention to their problems; for others, a way of collectivce art, of popular art, of poetical mural art, of living art, arto $\mathrm{n}$ the street, open air museum and so many other Brands it received then.
\end{abstract}

Key words: street art; Madrid; APSA; Juan Genovés; Lucio Muñoz; Arcadio Blasco; José Duarte; José Vento; Aragonés; Alcaín; Ángel Orcajo; Zamorano; Agustín Ibarrola; Guernica; Picasso; Prada Poole.

Sumario: 1. Barrios intervenidos artísticamente. 2.- Primeras asociaciones sindicales. 3.- Por una Cultura Popular. 4.- Más de quinientos metros cuadrados de murales. 5.Referencias bibliográficas.

\section{Barrios intervenidos artísticamente durante el último franquismo.}

La primera mitad de la década de los setenta fue, sin duda, para muchos, el despertar de una nueva época gracias al fin de la dictadura franquista, aunque para otros también significó la continuación de un calvario que nunca parecía acabarse, como bien ha demostrado la historia hasta la entrada de la democracia.

Entre muchos otros episodios de toda índole, quiero comenzar deteniéndome en el día 26 de abril de 1972, cuando fue aprobada la Comisión de Planeamiento y Coordinación del Área Metropolitana de Madrid, que incluía el Plan de Ordenación de la Ciudad Lineal que abarcaba 250 hectáreas $^{2}$. A grandes rasgos, supo-

2 Anónimo, “El área metropolitana aprueba”, $A B C$, Madrid, 26 de octubre de 1972. 
nía por un lado, acabar con el proyecto de Arturo Soria ${ }^{3}$ creado a finales del siglo XIX para hacer frente a los problemas de higiene, hacinamiento y transporte. Y, por otro, se trataba de una clara operación especulativa que arrasaba con todo un barrio de población inmigrante formado en el antiguo pueblo de Canillas y limítrofe con la Ciudad Lineal de Arturo Soria.

Aquel Plan de Ordenación se podría resumir en tres ideas básicas: la primera, pasar de treinta viviendas por hectárea a sesenta; la segunda, sobrepasar las dos o tres plantas originales hasta las ocho plantas en altura y, la última, edificar un $70 \%$ del suelo total.

El barrio de Portugalete ${ }^{4}$ sería, sin duda, el más perjudicado ya que sobre él cruzarían dos autopistas. Algunos auguraban que serían tan anchas como la propia calle de Arturo Soria ${ }^{5}$ y que se destruirían las casas recién construidas además de dividir el barrio en cuatro grandes sectores. Por este motivo, surgió con fuerza una iniciativa popular llamada Asociación de Vecinos del Barrio de Portugalete. Nacida hacia 1973, su lema común fue "Construir unidos un barrio" e intentaba dar solución a todos los problemas nacidos de ese Plan de Ordenación del 72 pero, también, combatir la dejadez que padecían muchos barrios periféricos por parte de las autoridades.

El más acuciante, el del urbanismo. Una urbanización que se llevaría a cabo por polígonos que, a su vez, estarían afectados por un sistema de compensación de terrenos que, en muchos de los casos, sufrirían la expropiación de los terrenos al no tener en propiedad un $60 \%$ de extensión. Le seguía el de la vivienda, que los mismos propietarios consideraban como "chabolas infectas, sin agua, con un servicio para 15 familias y algunas hasta sin servicio, mal ventiladas, llenas de

\footnotetext{
${ }^{3}$ El modelo de Arturo Soria estaba basado en la construcción de una ciudad alargada, cuya calle central tenía unos 50 metros de ancho y en donde se ubicaban servicios públicos, casas y en su parte central un ferrocarril eléctrico.

${ }^{4}$ La reconstrucción de este episodio de nuestra historia reciente española ha sido posible gracias a la generosa ayuda de José M. Julián Torrent y Santiago Martínez. Vid., http://historias-matritenses. blogspot.com.es/2011/04/barrio-de-portugalete-asociacion-de.html; y http://manuelrico.blogspot. com.es/2011/01/una-exposicion-que-enterro-el-urbanismo.html. Además de la escultura Carmen Perujo, el artista Ángel Aragonés y tanto otros miembros de la Asociación de Portugalete.

${ }^{5}$ Ballester, José María, “Arquitectura y urbanismo”, Blanco y Negro, Madrid, 5 de julio de 1975.
} 
humedad, pagando un alto alquiler, amontonados padres e hijos en un mínimo dormitorio ${ }^{6 \prime} ;$ y unido a éste, la ausencia de guarderías, centros sanitarios, instalación de aguas, alcantarillado y pavimentación de calles, limpieza general del barrio, instalaciones deportivas y recreativas, transportes, servicios de prensa y correos, residencias para ancianos o mercado.

A pesar de todas estas peticiones, la Asociación como tal no comenzaría a funcionar hasta su legalización. En enero de 1975 contaba con ciento cincuenta socios ${ }^{7}$, una Junta Directiva ${ }^{8}$ con ocho miembros, seis comisiones que se ocupaban de diferentes temas -cultura, urbanismo, servicios, social, juvenil y recreativa9- y un primer número del Boletín Informativo de la Asociación de Vecinos del Barrio de Portugalete en el que se pedía el esfuerzo y la unión de todos: "Con libertad y espontaneidad os esperamos. Queremos ser portadores y defensores de los intereses de todos. Por ello estaremos en permanente servicio... No olvidéis que lo que tenemos que hacer, y es grande la tarea que nos espera, tenemos que hacerlo juntos"10.

Dicha asociación de vecinos surgió a partir de la "Comunidad cristiana" del barrio de Portugalete que dirigía por entonces el sacerdote Manuel Fernández ${ }^{11}$. En un momento donde se deja entrever la ineficacia de la Iglesia en los barrios obreros, claramente anticlericales. Tras la Conferencia Episcopal de julio de 1968, se decide la coordinación de todas las secciones evangelizadoras del mundo obrero (parroquias, movimientos apostólicos, curas, etc.) que en los

\footnotetext{
${ }^{6}$ Anónimo, ¿Qué va a ser de nuestro barrio? Unámonos, Asociación de vecinos Barrio de Portugalete, Madrid, 1973.

${ }^{7}$ La Junta Directiva estaba formada por el Presidente, José María Julián Torrent; Vicepresidente, Javier Iglesias González-Nicolás; Secretario, Manuel Fernández Rodríguez; Tesorero, Rafael Cid Aldea y Vocales, Carmen Perujo Guerrero, Nicolás Herrero Puente, José Luis del Caz Izquierdo y Francisco Guzmán Terron.

${ }^{8}$ Boletín informativo, Asociación de vecinos, Barrio de Portugalete, núm.1, Madrid, febrero de 1975.

${ }^{9}$ Dichas Comisiones estaban formadas por los siguientes miembros: Cultural, Carmen Perujo; Juvenil, Javier Iglesias, Urbanismo, Manuel Fernández y Jesús Aguilar; Servicios, Francisco Guzmán y M. Fernández; Social, Nicolás Herrero Puente y recreativa, Ángel Garcés.

${ }^{10}$ Boletín Informativo, Asociación de vecinos, Barrio de Portugalete, op. cit.,

${ }^{11}$ Archivo personal de la escultora Carmen Perujo, documento, "Carta abierta", 25 de septiembre de 1975 .
} 
primeros años de 70 comienzan una progresiva independencia. Del desarrollo de esta crisis eclesiástica nacen las llamadas "comunidades base" cuya misión es reunir a cristianos comprometidos con los más oprimidos ${ }^{12}$. Así el plan de trabajo de dichas comunidades se centrará en los barrios como "único cauce eficaz para crear la Iglesia militante... Los grupos deben concretarse en la zona en la que van a trabajar (análisis de la realidad, nuevo rostro eclesial, medios pastorales), para que no se produzcan interferencias innecesarias en zonas correspondientes a los otros grupos... la comunidad cristiana se vive no aéreamente, sino en el seno del pueblo... La comunidad cristiana se oxigena y es fiel a su identidad y a su misión cuando sale de sus estrechos recintos y vive, sufre, lucha y libera en medio del pueblo donde vive"13.

Fig. 1.

Boletín de la Asociación de vecinos del Barrio de Portugalete.

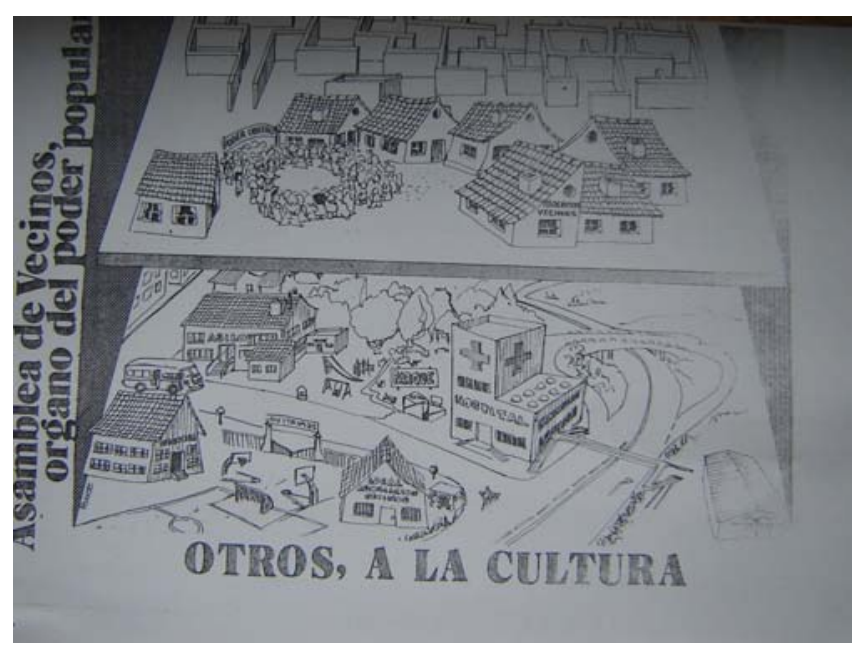

Coincidencia o no, también es el momento en el que el Presidente de la Junta Municipal del Ayuntamiento de Madrid, Julio Llantada, tras numerosas peticiones por parte de los vecinos de Portugalete, comenzaría a verificar públicamente los graves problemas de ese barrio del distrito de Hortaleza: "calles sin urbanizar, carencia de alcantarillado, cuenta entre sus edificaciones

\footnotetext{
${ }^{12}$ Archivo personal de la escultora Carmen Perujo. Documento, "La iglesia al servicio del evangelio", s/f.

${ }^{13}$ Archivo personal de la escultora Carmen Perujo. “Documento-campaña, 1975-1976. Creemos en una Iglesia liberadora y profética en nuestros barrios".
} 
tres patios o 'corralas' habitados por numerosas familias, cuyas reducidísimas viviendas constituyen un auténtico e inadmisible hacinamiento. He visitado uno de ellos llamado 'Patio del Abogado' donde en sólo dos habitaciones vive una familia con ocho niños"14.

Fueron las primeras llamadas de alerta por parte de la administración central, a pesar de las cuales aún no se conseguiría ninguna mejora reseñable para el barrio. En marzo de ese año, salía a la calle el número dos del Boletín Informativo, donde se ponía de manifiesto la actitud indiferente de la Junta Municipal, a la espera del informe de Gerencia de Urbanismo sobre la situación del barrio ${ }^{15}$; también se publicaba, eso sí, un primer triunfo de esas demandas: la concesión de un servicio de autobús desde la calle Milán a la parada de metro de Alfonso XIII.

El verano de 1975, que significó el preámbulo del desmoronamiento del régimen, comenzó con las graves noticias a las que la dictadura de Franco tenía acostumbrado al país. De todos son sabidas las habituales detenciones masivas gracias al aumento de la represión, a lo que habría de unirse, en septiembre, por un lado, el dictado del ministro de Información, León Herrera, centrado en las llamadas "normas de comportamiento" -que prohibían criticar al Jefe de Estado, al Príncipe Juan Carlos y al Presidente del Gobierno- y, por otro, los Consejos de guerra y condenas a muerte pendientes que se resolverían en este mismo mes y serían las últimas ejecuciones del franquismo en Madrid, Barcelona y Burgos. Todos esos acontecimientos suscitarán una lógica ola de protesta y condena dentro y fuera de España.

En ese clima convulso, y a tan sólo dos meses antes del desarrollo de estos acontecimientos, tiene lugar una protesta de carácter artístico en el barrio de Portugalete.

${ }^{14}$ Nachón, María Luz, "Condiciones inhumanas en el barrio de Portugalete", Informaciones, Madrid, 13 de febrero de 1975.

${ }^{15}$ La queja más generalizada era la de que no nos hacen caso y por ello pedían “...Tenemos que conseguir que venga a conocer nuestro barrio y a tener un coloquio público con los vecinos para buscar juntos el modo de dotar a nuestro barrio de todos los servicios necesarios y poder hacer así más grata nuestra convivencia" Boletín informativo, Asociación de vecinos, Barrio de Portugalete, núm.1, Madrid, marzo de 1975, s/p.

Melero Ginzo, Juan Antonio, “Arte en la calle”, Gazeta del Arte, Madrid, 30 de septiembre de 1975. 
Para algunos fue una toma de conciencia ciudadana, una forma de llamar la atención sobre sus problemas ante la inminente expropiación; para otros, un modelo de arte comunitario, de arte popular, de arte mural pictórico-poético, de arte vivo y arte en la calle, de museo al aire libre, de arte que había bajado al nivel de la calle y tantos otros calificativos ${ }^{16}$ que recibió en su momento.

Figs. 2-3.

Programa de las fiestas del Barrio de Portugalete, 1975.
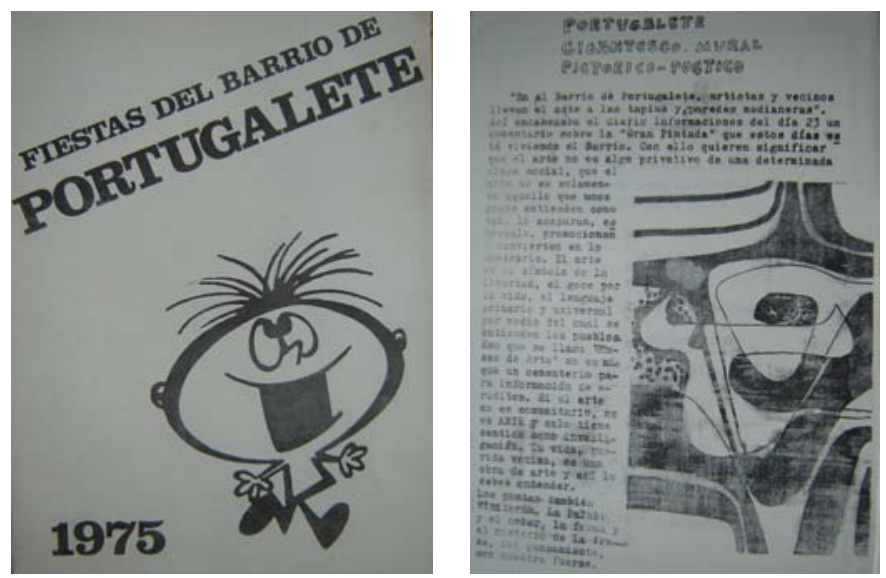

Lo cierto es que todas estas definiciones estuvieron presentes y convivieron durante un tiempo en aquellas pintadas que recorrieron los muros de una superficie de más de $500 \mathrm{~m}^{2}$.

Por un lado, fue una convocatoria más de atención pública a las autoridades ante los graves problemas del barrio de Portugalete: desahucios, abandono, falta de servicios, especulación o deficiencia urbanística y, por otro, un acercamiento del arte al pueblo. Podría considerarse como una manifestación

\footnotetext{
${ }^{16}$ Anónimo, "En el barrio de Portugalete, artistas y vecinos llevan el arte a las tapias y paredes medianeras", Informaciones, 23 de junio de 1975; Anónimo, "Los artistas del barrio", Triunfo, Madrid, 12 de julio de 1975; Ballester, José María, “Arquitectura y urbanismo", op.cit; Cabezas, "Mentidero de la villa. Fiestas y cultura popular en Portugalete", $A B C$, Madrid, 30 de junio de 1976; De Prado, “Quieren formar sus juntas de compensación”, Arriba, Madrid, 10 de julio de 1975; Gil Mintxa, "Arte en la calle para la calle”, Gaceta Ilustrada, julio de 1975; Muñoz García, "Los murales y la estética urbana", Gazeta del arte, 30 de septiembre de 1975; Prieto Barral, María Fortunata, "L'art dans la rue á Madrid", Galerie jardins des arts, Paris, diciembre de 1975 y Pyresa, “Una manifestación artística inédita”, Sur, 15 de julio 1975.
} 
artística inédita, si se tiene en cuenta sus dimensiones y el alto número de participantes, entre artistas, poetas, cantantes, actores y vecinos. Sin embargo, también tiendo a pensar más en una estrategia político-intelectual, llevada a cabo por un grupo mayoritario de artistas comprometidos con organizaciones sindicales y bajo el nombre aún ilegal de la Asociación de Artistas Plásticos.

\section{Primeras Asociaciones Sindicales.}

Dicha Asociación se forma a finales de los años 60, cuando gran parte de la sociedad artística española luchaba por la amnistía, la libertad de expresión, de reunión y de asociación perdidas durante el franquismo.

Desde hacía tiempo, se intentaba canalizar todo tipo de tendencias -políticas, sociales, económicas- surgidas como consecuencia de esa inflexible dictadura y que, poco a poco, se fueron manifestando en continuas agitaciones obreras y estudiantiles. En esos mismos años se formó en la clandestinidad la Asociación de Artistas Plásticos, después de varias asambleas celebradas en la Escuela Superior de Bellas Artes de Madrid. Ante la imposibilidad de crear una asociación, aún ilegales en esa época, se pensó ingresar en la Organización Sindical Española, conocida como el Sindicato Vertical (1940-1976) y dividida en diversas ramas de producción. En el caso de las artes, bajo el amparo de ANSIBA (Asociación Nacional Sindical de Bellas Artes), pero se desechó por la ineficacia de la corporación ${ }^{17}$. Finalmente, se ideó otra fórmula de agrupación llamada APSA, Promotora de Actividades Plásticas. Sociedad Anónima. Desde esa plataforma de acción comenzaron a realizarse varias mesas democráticas y el 25 de abril de 1975, y todavía sin legalizar como asociación, se constituyó la primera junta democrática de los artistas plásticos de Madrid, en busca de mayores libertades y autonomías. Y es que un año antes, en julio de 1974, se había constituido en París, impulsada por el Partido Comunista de España (PCE), la Junta Democrática de España como oposición al franquismo y como intento de articular una gran masa social mediante Juntas democráticas locales y sectoriales.

En aquella primera junta democrática de los artistas plásticos se manifestaba el enorme vacío cultural creado desde 1939 y agravado con la prohibición de

\footnotetext{
${ }^{17}$ Centro de Documentación y Biblioteca MNCARS, SIG. 895/2
} 
cualquier manifestación cultural no afín al régimen. A ello se unían numerosas reivindicaciones que proclamaban el desamparo total del artista ante la sociedad. La conclusión fue la redacción de un documento con la petición de siete derechos basados: libertad de reunión, asociación y expresión; amnistía para los artistas represaliados por razones culturales o ciudadanas; democratización del acceso y difusión de la cultura por medio del establecimiento de cauces no comerciales y de la autogestión; abolición total de la censura; participación en la política cultural a todos los niveles; reforma total de la enseñanza de las artes plásticas y control del patrimonio artístico nacional.

Al mismo tiempo, se apoyaban en los "doce puntos"18 del PCE, redactados por Antonio García-Trevijano y proclamados como vía para la evolución democrática del Estado franquista y, en su defecto, la ruptura del mismo. Además de su trascendental significado, me interesa transcribir cómo termina dicho documento:

${ }^{18}$ Los doce puntos de su programa, redactados por Antonio García-Trevijano, eran los siguientes:

1. La formación de un gobierno provisional que sustituya al actual, para devolver al hombre y a la mujer españoles, mayores de dieciocho años, su plena ciudadanía mediante el reconocimiento legal de todas las libertades, derechos y deberes democráticos.

2. La amnistía absoluta de todas las responsabilidades por hechos de naturaleza política y la liberación inmediata de todos los detenidos por razones políticas o sindicales.

3. La legalización de los partidos políticos, sin exclusiones.

4. La libertad sindical y la restitución al movimiento obrero del patrimonio del Sindicato Vertical.

5. Los derechos de huelga, de reunión y de manifestación pacífica.

6. La libertad de prensa, de radio, de opinión y de información objetiva de los medios estatales de comunicación social, especialmente en la televisión.

7. La independencia y la unidad jurisdiccional de la función judicial.

8. La neutralidad política y la profesionalidad, exclusivamente militar para la defensa exterior, de las Fuerzas Armadas.

9. El reconocimiento, bajo la unidad del Estado español, de la personalidad política de los pueblos catalán, vasco, gallego y de las comunidades regionales que lo decidan democráticamente.

10. La separación de la Iglesia y del Estado.

11. La celebración de una consulta popular, entre los doce y los dieciocho meses -contados a desde el día de la restauración de las libertades democráticas-, con todas las garantías de libertad, igualdad de oportunidades e imparcialidad, para elegir la forma definitiva del Estado.

12. La integración de España en las Comunidades europeas, el respeto a los acuerdos internacionales y el reconocimiento del principio de la coexistencia pacífica internacional. 
... llamamos a todos los artistas a desarrollar un trabajo teórico sobre la alternativa cultural que proponemos, a exponer de forma concreta la estructuración bajo formas democráticas del ejercicio de nuestra profesión, sobre todo, a idear y poner en práctica formas de lucha en las que pueda participar la mayoría del sector y a estrechar sus contactos con otras Juntas Democráticas, concretamente con las del barrio donde vive ${ }^{19}$.

En mi opinión se buscó la unión entre sectores culturales y ciudadanos bajo un programa político que proporcionó grandes movilizaciones democráticas. Sin duda, éste es uno de los vínculos directos con los vecinos del barrio de Portugalete, de modo que aquellos murales se convierten en una gran manifestación política y artística.

Citábamos más arriba que la Junta Directiva de la Asociación de Portugalete estaba formada, entre sus vocales, por la escultora Carmen Perujo, quien también dirigía la comisión de trabajo para el barrio centrada en asuntos culturales. En aquella época Carmen Perujo vivía en el barrio y era la mujer del escultor Arcadio Blasco, también vocal de la Junta Directiva del barrio en 1976, siendo ambos miembros de la Asociación de Artistas Plásticos. En 1977, Arcadio será elegido Presidente de dicha Asociación; Rafael Canogar, como vicepresidente; Eduardo Arenillas, como secretario y Salvador Soria, como Tesorero. Todos ellos participaron asimismo en aquella muestra al aire libre.

\section{Por una Cultura Popular.}

Desde el principio, uno de los fines de la futura Asociación de Artistas Plásticos fue el análisis de la situación general del artista y del arte en España. Más aún cuando ya en 1970 una delegación española de artistas (Marisa González, Eduardo Arenillas y Angiola Bonnani) había presentado en el Congreso Internacional de la AIAP, organizado en Belgrado ${ }^{20}$, una conferencia sobre la formación profesional del artista y el concepto oficial del arte. También habían leído un telegrama -lógicamente, muy politizado- firmado entre otros por Canogar, Chilli-

\footnotetext{
${ }^{19}$ Centro de Documentación y Biblioteca MNCARS, SIG. 875/7

20 Vid., Albarrán Diego, Juan, “Estéticas de la resistencia en el último franquismo: entre la investigación lingüística y la consolidación del movimiento asociativo", Artigrama, núm. 25, Zaragoza, 2010.
} 
da, Genovés, Miró, Mompó, Muñoz, Oteiza, Picasso, Saura, Sempere y Tàpies. A partir de entonces, la AIAP les serviría de plataforma de actuación, tanto en el exterior como en el interior de España.

Como decíamos, ante las sucesivas negativas de legalización por parte de la administración franquista, la Asociación de Artistas Plásticos funda en $1972^{21}$ la Promotora de Artistas Plásticos. Sociedad Anónima (APSA), con seis comisiones cuyos miembros encargados de su funcionamiento y estructuración eran Lucio Muñoz, Arcadio Blanco, Tito y Francisco Escalada. Una de aquellas comisiones se ocupaba de la "Función del arte en la sociedad", centrada en el estudio de las relaciones entre artista y obra de arte en su medio social. Entre sus objetivos prioritarios se encontraba el de tratar de elevar el nivel cultural en lo concerniente al arte en todos los sectores de la sociedad, especialmente en aquellos con menos facilidades para su conocimiento, ya que opinamos que el arte tiene como fin una función humanizadora y no el ser un objeto de lujo 22 .

${ }^{21}$ Entre los primeros miembros interesados por la Asociación cabe destacar: Alfredo Alcaín, Julio Álvarez, Francisco Álvarez, José Luis Alexanco, Manuel Alcorlo, Elvira Alfageme, Ortiz Alfaro, Vicente Anestoy, Eduardo Arenillas, Ángel Aragonés, Manuel Ayllón, Francesc Artigau, Amalia Avia Isabel Baquedano, Barahona, Nasio Bayarri, Dionisio Blanco, Arcadio Blasco, Juan Barjola, Francisco Barón, Bey, Manuel Calvo, Ignacio Juan Manuel Caneja, Rafael Canogar, Cárdenas, José Luis Casado, Federico Calabuig, Edurado Carretero, Jesús Cauloga, Agustín de Celis, Andrés Cillero, José Conde Corbal, Francisco Cortijo, Alberto Corazón, Francisco Cruz de Castro, José Duarte, José Luis de Dios, Francisco Echauz, María Eugenia Escrivá, Francisco Escalada, Fernando Escrivá, Francisco Farreras, Trinidad Fernández, Juan Francés, Alonso Fraile, Juan Genovés, José Guinovart, Marisa González, José Luis Gómez Perales, Enrique Gran, Juan Giralt, Luis Gordillo, María Girona, Marcelino Gómez Pintado, Manuel de Gracia, Hernández Pijoán,José María Iturralde, Marcos Irizarry, Juan José Junquera, Francisco López, Miguel Ángel Lombardia, Antonio Lorenzo, Antonio López García, Julio López Hernández, Custodio Marco, Antonio Marcoida, Abel Martín, Ángel Medina, Daniel Merino, Manuel Millares, Manuel Molezún, Manuel Mompó, Juan Luis Montero, María Montero, Pedro Moreno, Lucio Muñoz, Ángel Orcajo, Ottoris, Pascual Palacios Tardez, Manuel del Palacio, Adela Parrondo, Raimundo Patiño, Javier Pamplona, Antonio Povedano, Emilio Prieto, Poblador, Rafols Casamada, Manuel Rivera, Rubio Camín, José Luis Sánchez, Santacatalina, Julián Santamaría, Eduardo Sanz, Carlos Sanz, Juana Saoriz Diaz Joan Semmell, Eusebio Sempere, Pablo Serrano, Fernando Somoza, Salvador Soria, Rafael Solves, Antonio Suárez, Eduardo Urculo, Manuel Valdés, José Vento, Fernando Verdugo, Salvador Vitoria, Ignacio Wenceslao, Yraola, Ricardo Zamorano, Antonio Zarco...

${ }^{22}$ Centro de Documentación y Biblioteca MNCARS, SIG. 867/4. 
Otra de aquellas funciones era la de comunicar y cumplir una función social. Por ello se divulgaron octavillas entre los artistas centradas en nuevas alterativas para el arte:

Hacer un arte, digámoslo así, es un trabajo. Es un trabajo que contribuye a la cultura. Hacer arte ni es privativo de nadie; es un lenguaje que debe ser universal, al que todos tenemos derecho de expresión, de conocimiento, y de adquisición. Hacer arte no debe ser patrimonio de una élite, ni debe ser accesible a un solo y determinado grupo social; el arte es un patrimonio universal y rechazamos la idea de propiedad intelectual.

INTENTAREMOS

Procurar la difusión del arte para una mayor integración de la comunidad en el él. Salida del arte a la calle, exposiciones itinerantes, charlas, coloquios, etc.

Fomentar y apoyar todo tipo de iniciativa dentro de las artes plásticas. Enriquecer nuestra formación teórico-práctica en aras de un claro entendimiento social23.

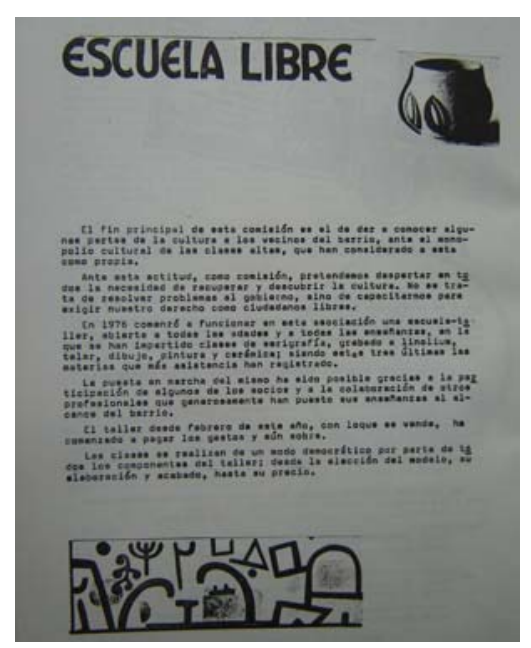

Fig. 4.

Panfletos de la Asociación del Barrio de Portugalete

Desde los años sesenta se intentó, tanto en Europa como en Estados Unidos, eludir la mercantilización del objeto artístico huyendo del sistema establecido de galerías y con la intención de sacar el arte a la calle, aunque para ello hubiera que acabar con la imagen del artista como individuo aislado. A ello habría

${ }^{23}$ Centro de Documentación y Biblioteca MNCARS, SIG. 867/15 
que sumar la proliferación de propuestas en las que la ciudad se convirtió en nuevo escenario artístico a través de performances, esculturas o pintadas. Formaba parte de lo que se denominó "arte comunitario". Compuesto por el artista y por los miembros de una comunidad, se luchaba por los problemas de zonas deprimidas a través de una actividad colectiva y su objetivo ideal era la trasformación social, casi siempre acompañadas por acciones políticas ${ }^{24}$.

En julio de 1974 los artistas plásticos tienen la oportunidad de acceder al Coloquio Internacional sobre el papel y la importancia del artista en la vida contemporánea, organizado por las Naciones Unidas para la Educación, la Ciencia y la Cultura, aunque, como indica en el documento, su distribución fue limitada en España. Allí, una de las sesiones está dedicada a los deberes y obligaciones del artista hacia la sociedad y viceversa.

Las relaciones entre el artista y el público parecen ser más estrechas: si el artista sigue brindando su obra a los demás, el público, cada vez menos pasivo, se convierte frecuentemente en un espectador o un auditor que aspira a participar en la creación artística. Ese nuevo público, nacido del progreso de los medios de comunicación y del desarrollo de la educación, pretende no quedar al margen del fenómeno, colectivo a su juicio, de la creación artística y asistimos cada vez más a manifestaciones en las que el creador no es uno solo, sino en las que un grupo integra y armoniza la aportación de cada uno $0^{25}$.

En España, el interés -cada vez mayor- de la accesibilidad del público a los mensajes artísticos y de la participación grupal en la creación de una obra de arte había comenzado ya con grupos como Equipo 57 o Estampa Popular, ésta último a través de la difusión de grabados de comprensión sencilla y de una ideología cercana a la de APSA, basada en mejoras para el artista y un arte con función social $^{26}$. Creo que más paradójico fue el resultado en Portugalete, donde se cumplieron las propuestas de los artistas plásticos: función social, integración de un barrio, artista y público activos, ascenso del nivel cultural -aunque sólo fuera por unos días- o salida del arte a la calle.

${ }^{24}$ Vid., Parreño (2002).

${ }^{25}$ Centro de Documentación y Biblioteca MNCARS, SIG. 875/18.

${ }^{26}$ Vid., De Haro García (2010). 
Muchas de aquellas tertulias, también llamadas asambleas, entre vecinos y artistas estuvieron moderadas por el escultor Arcadio Blasco y se centraron en la accesibilidad de las artes a la masa popular. El propio artista afirmaba:

Desde sus orígenes, la cultura ha sido acaparada y utilizada por la clase dominante. El productor de cultura ha sido manipulado y sus obras han servido para justificar la opresión. Al calor de la radicalización de las luchas obreras y populares en España, los artistas plásticos somos conscientes de nuestro papel en la sociedad... Llevar el arte a la calle para que la acción plástica sea conocida, rescatar la creatividad de las manos especulativas y volverlos a su lenguaje de comunicación al servicio del hombre. Este es el sentido de las pinturas murales que se están extendiendo por todos los barrios del territorio español27.

De hecho, los murales fueron entendidos así, tal y como muestra gran parte de la prensa escrita del momento. La revista Triunfo publicaba al respecto:

Algunos vecinos expresaron su incapacidad para entender el trabajo realizado por los artistas y manifestaron el deber que tiene el artista de hacer un arte para el pueblo. Respondían los artistas: al pueblo no se le prepara para entender el arte, para tener acceso al hecho artístico. Ciertos vecinos subrayaron la importancia social de la iniciativa de los artistas en el barrio, ya que al margen del problema de la comprensión de la obra realizada, el hecho de haberlo intentado había significado un apoyo a la comunidad de Portugalete ${ }^{28}$.

Una vez más, los artistas plásticos afirmaban la importancia hacia una reestructuración de algunos aspectos de la sociedad, como la manipulación de los medios de difusión y la aparición de un modelo de actuación democrático o una nueva política cultural. Para APSA significó, además, uno de los primeros ensayos con los que indagar no sólo en las funciones del arte sino también entre el arte y la comunicación de masas:

La sociedad española vive en compartimentos estanco, los artistas viven y desarrollan su actividad en un mundo propio y para unas clases sociales; la razón de

\footnotetext{
27 Cortometraje de Esquivel, Humberto, Por una cultura popular. Barrio de Portugalete en Fiestas, junio de 1976.

${ }^{28}$ Anónimo, “Los artistas en el barrio", op. cit.
} 
esta incomunicación no es imputable a unos y a otros, sino a la forma de estar estructurada nuestra sociedad: solo una transformación de ésta puede permitir la fusión del artista con el pueblo. En esta situación, intentar someter la práctica artística a unos cánones de inteligibilidad para que fuera comprendida por todos, podría significar la paralización del arte... No se trata de 'descender' al nivel de una determinada preparación cultural del pueblo, sino de elevar el nivel cultural del mismo ${ }^{29}$.

Aquel inmenso conjunto de obras recibió el premio de la revista Reseña en diciembre de 1975 por su función estético-social, además de ser considerada como una obra de arte total y comunitaria con el objeto de dar lugar a una acción lúdico-creativa y que hace referencia a un hecho de la vida cotidiana de un sector de población: la defensa del 'hábitat'30.

\section{Más de quinientos metros cuadrados de murales.}

El inicio de los murales coincidió con el desarrollo de las fiestas de San Pedro y San Pablo del barrio de Portugalete, durante los días 25 y 26 del mes junio de 1975. Una comisión del barrio -entre la que se encontraba la participación activa de muchos integrantes de APSA- decidió realizar una acción en forma de protesta para insistir en los problemas del barrio y en la nula intervención de los vecinos en ese Plan de Urbanismo.

De allí surgieron varias comisiones de trabajo de artistas plásticos formadas además por los propios vecinos. En tres días se llevaron a cabo casi más de cincuenta murales reivindicativos re-partidos entre medianeras de las viviendas, tapias y alcantarillas. Un grupo podía estar formado por tres o cinco personas, que acompañaban al artista en la ejecución del mural. Constituían los llamados "Equipos del barrio" y, junto a la firma del artista, aparecía ese nombre como sello colectivo del grupo. Ellos mismos portaban la pintura en cubos, orinales y botellas, se improvisaron andamios y se intercambiaron cucharas, pinceles y brochas ${ }^{31}$.

\footnotetext{
${ }^{29}$ Ibíd.,

${ }^{30}$ Anónimo, “Premios reseña 75”, Doblón, Madrid, 12 de julio de 1975.

${ }^{31}$ Anónimo, "En el barrio de Portugalete, artistas y vecinos llevan el arte a las tapias y paredes medianeras", op. cit.,
} 


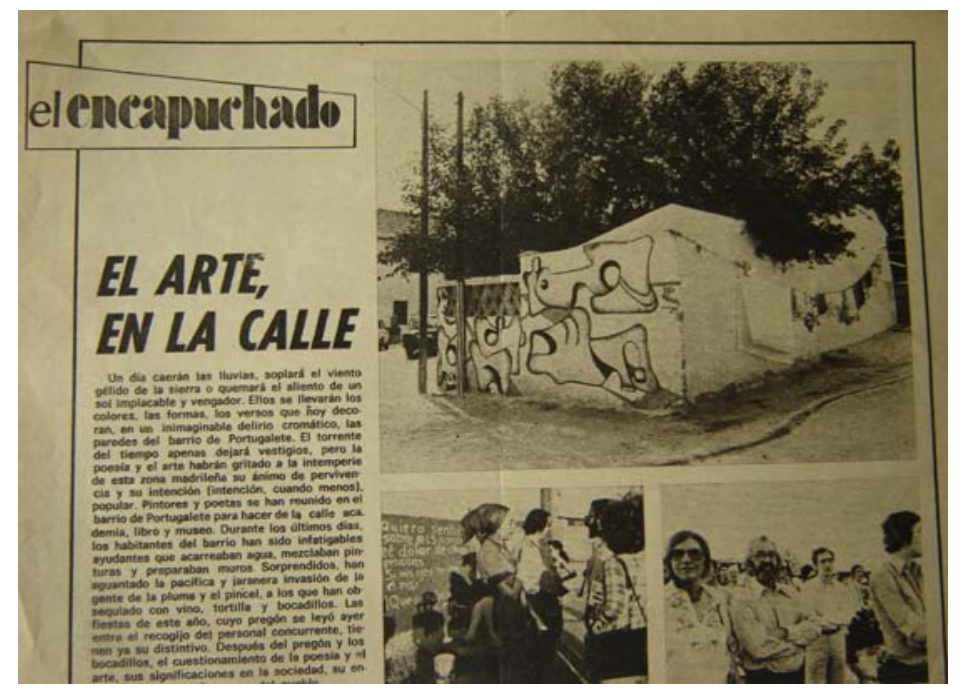

Fig. 5. Arriba, Madrid, 1975.

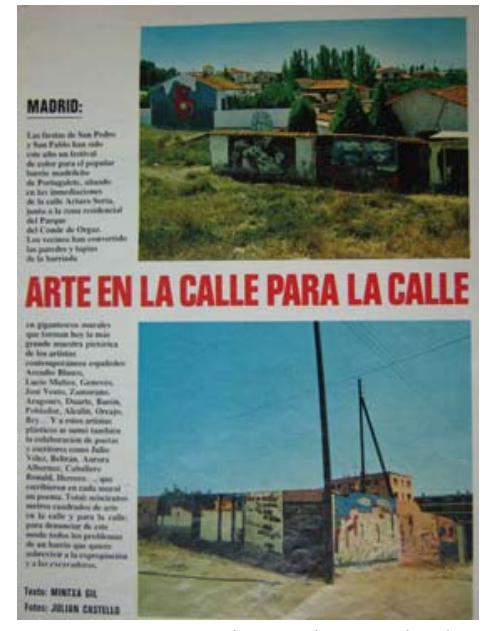

Fig. 6. Gaceta Ilustrada, Madrid, julio de 1975.

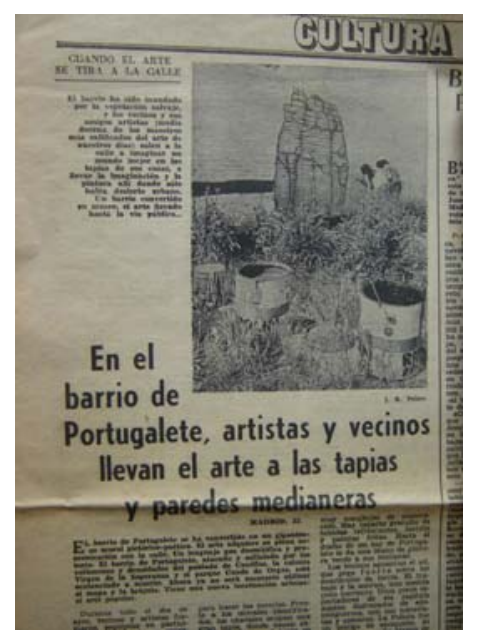

Fig. 7. Informaciones, Madrid, 23 de junio de 1975.

Para algunos la acción fue considerada como la desmitificación del artista ante el pueblo ${ }^{32}$. Lo cierto es que cada uno de ellos siguió su propia tendencia artística, desde lejanos ecos el cubismo y el surrealismo de las primeras vanguardias

32 Muñoz García, “Los murales y la estética urbana”, op.cit., 
hasta el realismo más crítico pasando por el informalismo, el experimentalismo, el arte pop o el arte óptico. Gerardo Vielba, presidente de la Real Sociedad Fotográfica, llegó a calificarlo incluso como una versión suburbana del land art (Vielba, 1976: 17). Así mismo, los fotógrafos Fernando Bedmar, José Ma Castillo, Pablo Culebras, Raúl Jiménez y Enrique Peral, miembros de esta misma Sociedad, rindieron un homenaje al evento realizando un conjunto de fotografías en donde se quiso captar en gráfico documento el hecho, fijarlo en su deteriorada vivencial muestra, tal como hasta ahora mismo, entre el hostigo del tiempo y del hombre se defiende (Ibíd, 1976: 17).

Acompañando a los murales aparecían versos de poemas de Aurora de Albornoz, Pedro Beltrán, Caballero Bonald, M. Conde, Ángel González, Horacio Guarany, José Hierro, R. Lorente, Julián Marcos, Antonio Leyva, Lucena, Enrique Páez y Veléz, entre otros.

De todas aquellas tendencias, creo que el realismo fue la opción dominante. Desde los años sesenta se había comenzado a escribir, y no sin debates, sobre los nuevos modos de realismo. Uno de ellos, cercano a los textos de Marx y Engels como el realismo social y de compromiso; y el otro, un realismo expresivo, pero ambos muy conocidos ya desde la República. A ello se suman los grupos como Estampa Popular, creado a partir de la disolución del Equipo 57, cuya finalidad era hacer un realismo crítico para denunciar los abusos del régimen y forjar la imagen del pueblo campesino y urbano sometido a la miserable y dura vida del régimen, como veremos en los murales de José Duarte.

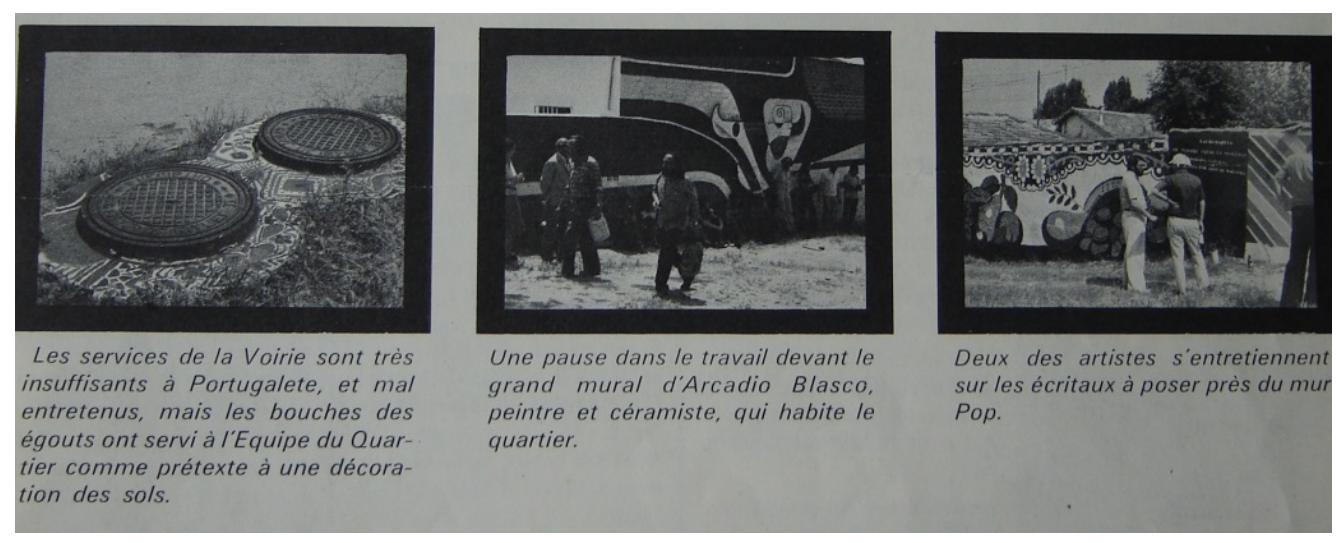

Fig. 8. Galerie jardins des arts, Paris, diciembre de 1975. 
En 1966 se publican dos importantes libros. El primero, Crítica del gusto de Galvano della Volpe, traducido al castellano por Manuel Sacristán y publicado por la editorial catalana Seix Barral, donde se apoyaba la condición artística del realismo. El segundo es El realismo entre el desarrollo y el subdesarrollo, de Valeriano Bozal, donde se analizaba el arte comprometido con la realidad, desde el estudio teórico del realismo a las relaciones de la vanguardia con lenguaje realista. Era un momento crucial en el que el informalismo sufría una enorme crisis y el auge del arte pop era cada vez mayor.

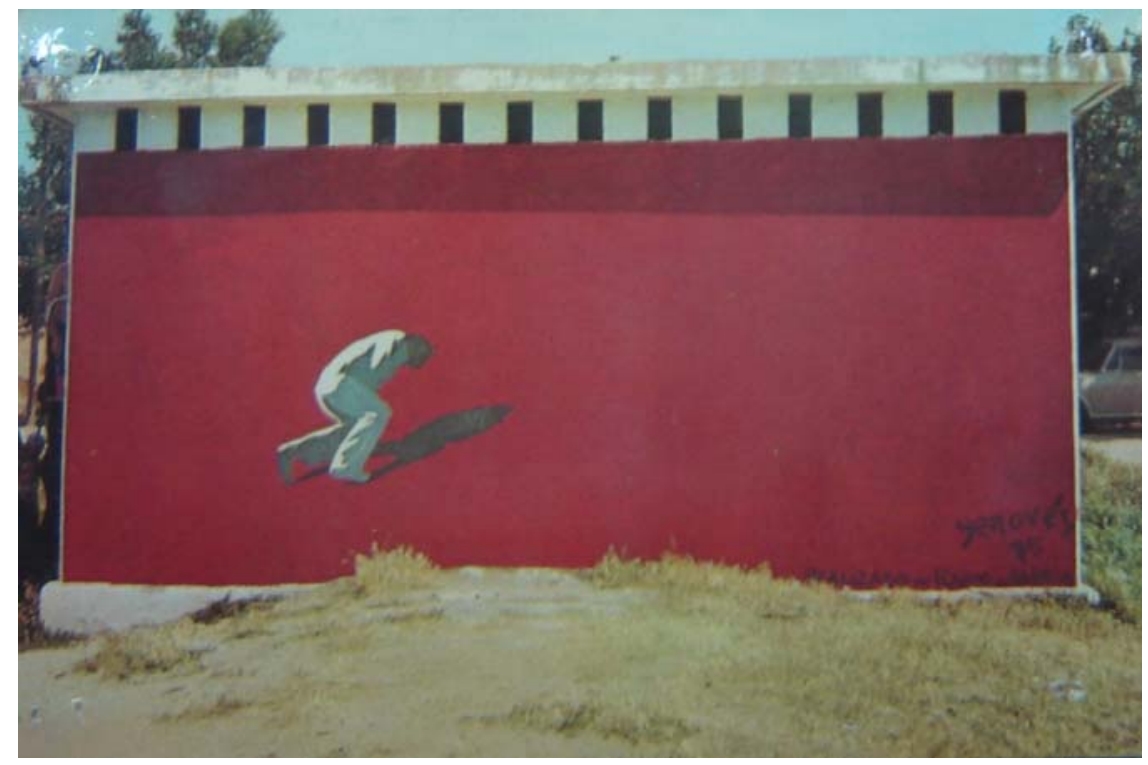

Fig. 9. Juan Genovés y el Equipo del Barrio.

De todos los murales quiero resaltar aquellos que mayor interés suscitaron en las críticas artísticas aparecidas en prensa, que además habían sido realizados por los miembros más combativos con el régimen. Sin duda alguna, comenzar por la figura de Juan Genovés supone todo un referente para esta época del tardofranquismo. Detenido en más de una ocasión por sus ideales políticos, en Portugalete realizó un inmenso mural que aludía al estado de excepción que se vivía en esos momentos. Centrado más en el individuo derrotado y abatido que en la masa de perseguidos.

Lucio Muñoz tituló su mural Homenaje póstumo a Arturo Soria, como homenaje al creador de la Ciudad Lineal. La obra iba acompañada de una cerámica 
que tuvieron que retirar por miedo a su sustracción. En la parte inferior derecha, Caballero Bonald escribió: Este muro que respira. Aquí sólo se quedan los que no vuelven. Se trataba de una pintura collage que resaltaba ese gusto por el color negro, el llamado negrismo, impuesto en el informalismo de fines de los cincuenta y que aludía directamente al mito de la España Negra. El mural de Lucio Muñoz experimentaba un cambio en su pintura, como muy pronto se podría ver en la nueva galería de Juana Mordó. El artista manejaba dos registros; por un lado, el gusto por la materia manipulada, y por otro, el arte social, comprometido o una nueva figuración más dramática (Trabazo, 1977).

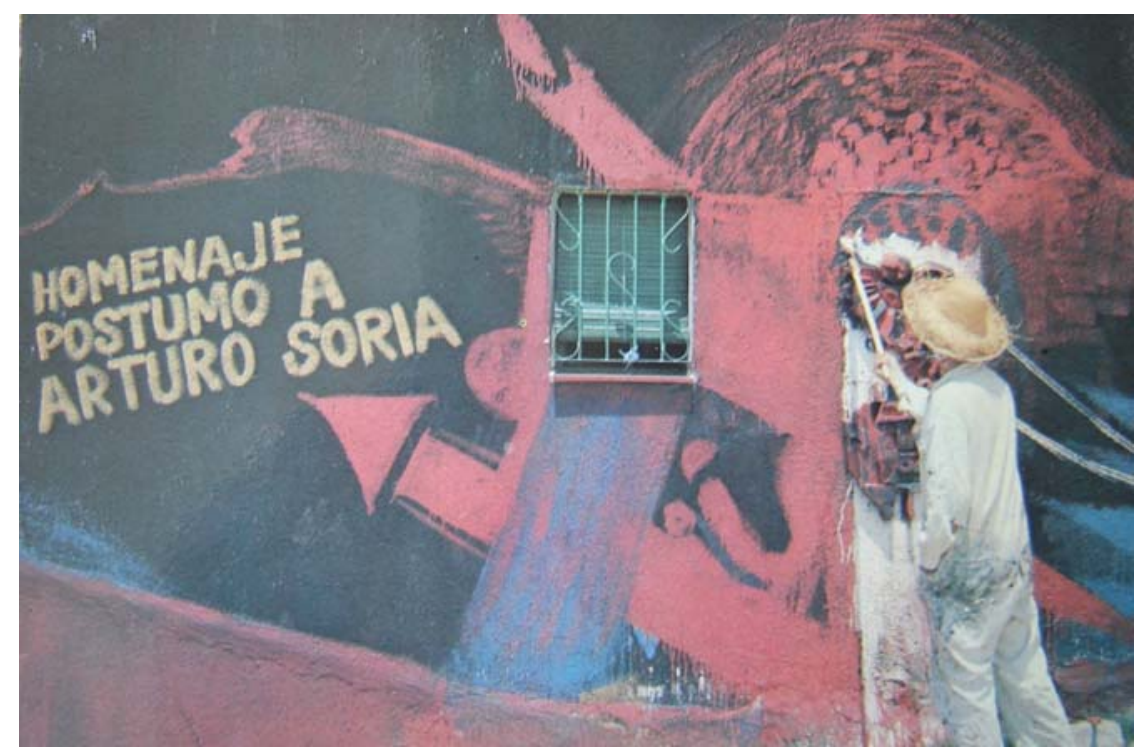

Fig. 10. Lucio Muñoz y el Equipo del Barrio, Homenaje póstumo a Arturo Soria.

Arcadio Blasco presentaba Proyecto ornamental para el toro-cercenador de dedo decisorio vergonzantemente agigantado. No era, precisamente, la técnica habitual del artista, acostumbrado a presentar obras escultóricas de grandes perforaciones. Sí lo era, en cambio, la temática utilizada, centrada en la explícita alusión a la represión del individuo en esa sociedad de la que él era testigo privilegiado ${ }^{33}$.

${ }^{33}$ Vid., Cuatro artistas alicantinos, Sala de exposiciones Alicante, enero-febrero de 1976. 

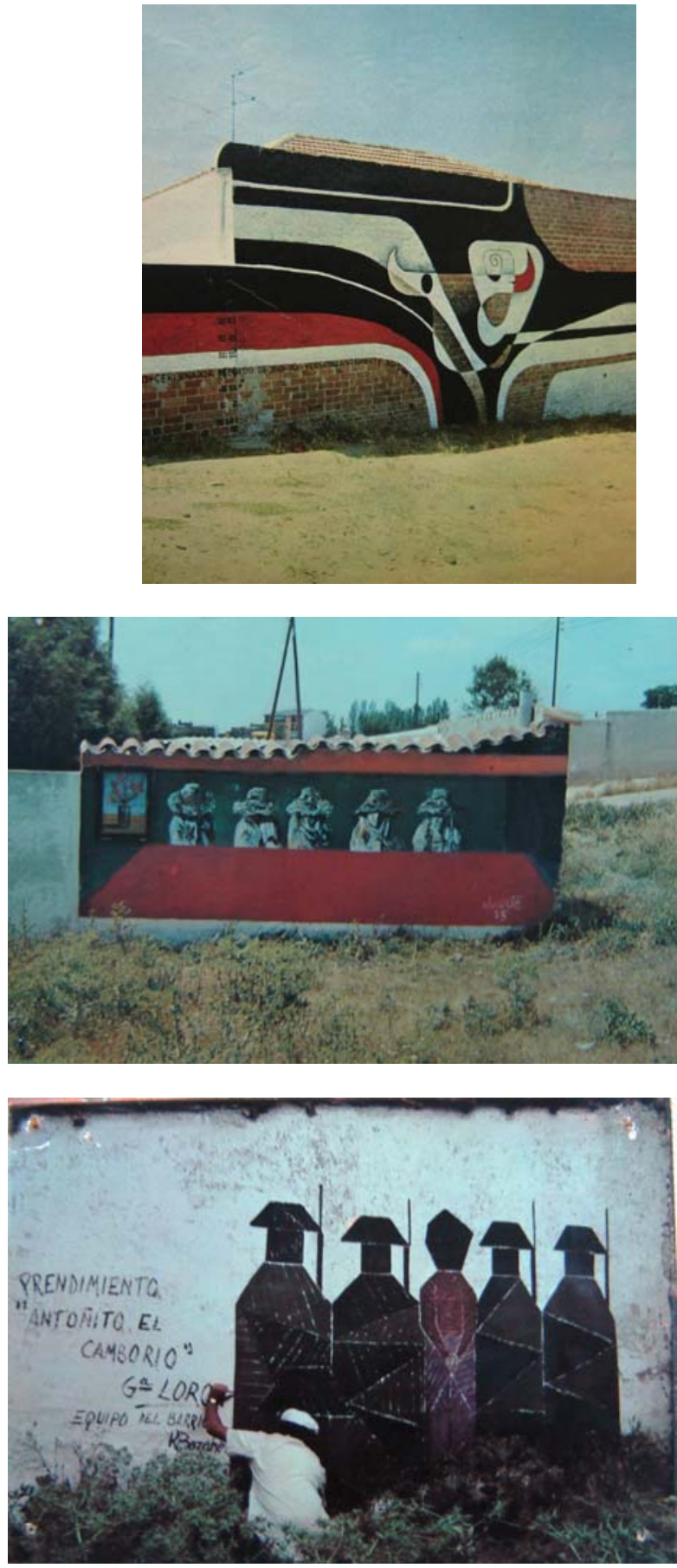

Fig. 11.

Arcadio Blasco y el Equipo del Barrio, Proyecto ornamental para el toro cercenador de dedo decisorio vergonzantemente agigantado.

Fig. 12.

José Duarte, Campesinas.
Fig. 13.

Barahona y el Equipo del Barrio, Prendimiento "Antoñito, el Camborio". 
Fig. 14.

José Vento, Las tres gracias

Fig. 15.

Ángel Aragonés, La araña y el gallo son amores distintos

Fig. 16.

Zamorano, Descomposición de Franco.
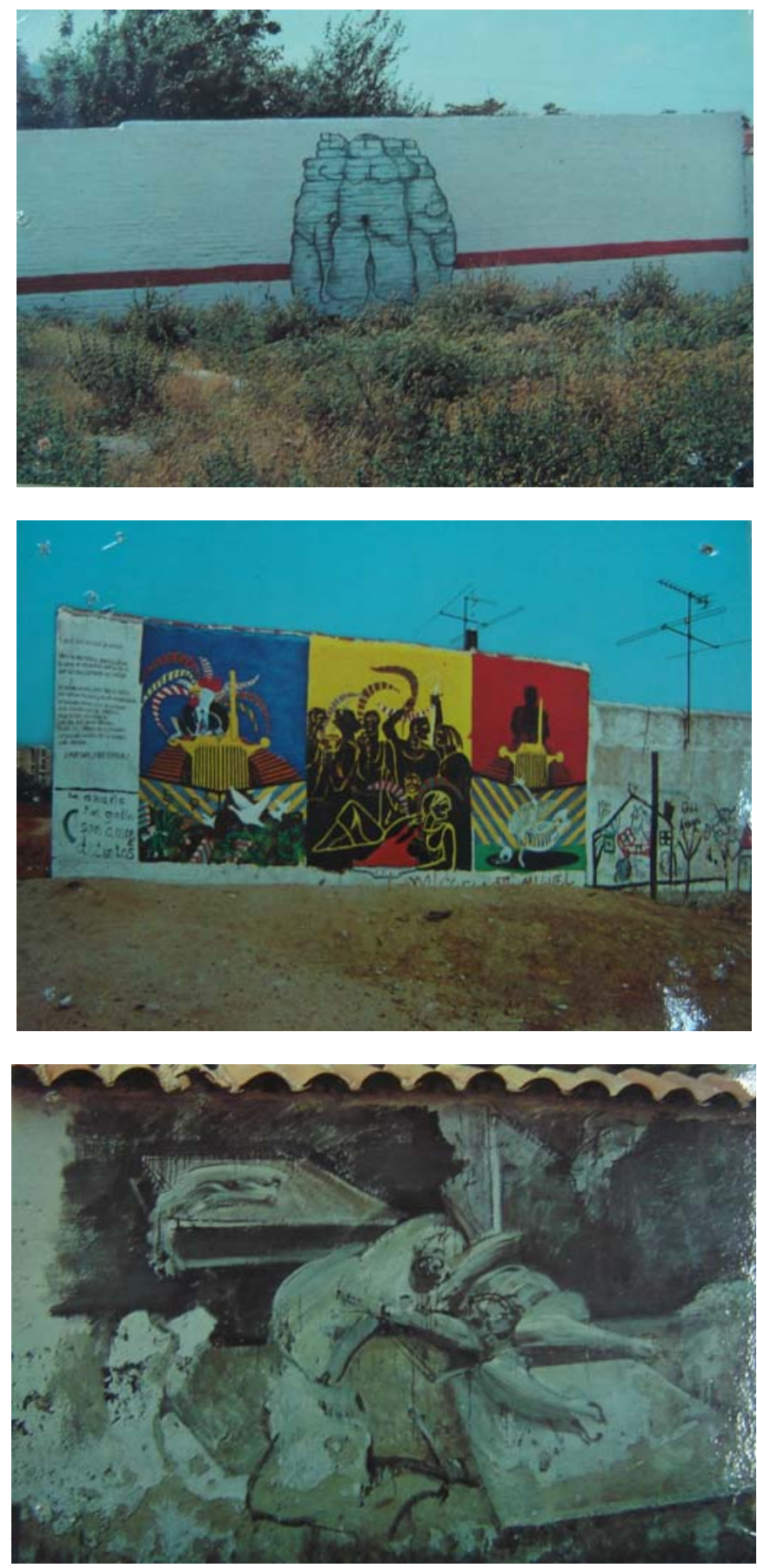

Arte y Ciudad - Revista de Investigación

2013 (Junio) n 3 (I) Extraordinario 
El enorme mural de José Duarte representaba uno de sus temas preferentes de aquella época, las campesinas. Reflejo del mundo agrario de su tierra natal, Andalucía, y presentadas como verdaderos prototipos, aparecen cinco campesinas, algunos de cuyos rostros quedan totalmente tapados por enormes sombreros de paja. Es otra forma más de crítica social a través del realismo popular, denunciando la pobreza, la incomunicación o el abandono ${ }^{34}$. Acompañando al mural aparecía un poema de José Hierro:

Días de ayer nos modelasteis crudamente, a vuestro modo.

Días de ayer, ¡Dios os perdone lo que habéis hecho de nosotros!

Barahona inmortalizó uno de los poemas del Romancero Gitano (1924-27) de Federico García Lorca, Prendimiento "Antoñito, el Camborio". Al igual que el poeta, Barahona adapta la imagen de la muerte tan presente en los próximos sucesos del 1976. José Vento presentó Las tres gracias, que posteriormente fueron reproducidas en platos de cerámica. Alcaín exhibió voluminosas frutas de estilo pop. El mural de Aragonés, La araña y el gallo son amores distintos, presentaba diferentes símbolos que delataban, entre otros, los colores de la bandera republicana, hoces, tractores y un pájaro putrefacto surrealizante muy en la onda del Grupo Realidad o Equipo Crónica. Ángel Orcajo, con alusiones a la misma temática militante que los anteriores, desplegaba un enorme decorado de casas de formas cubistizantes oteadas por una inmensa figura que lo dominaba todo.

Quizás sea Zamorano el artista que de una forma más directa aludía al dictador. En plena agonía, y a menos de cinco meses de esa muerte tan ansiada por muchos, aparece el reflejo de la descomposición de Franco. A esas formas expresionistas, de enormes pinceladas grises y deshechas, acompañaba una poesía de Aurora Albornoz que aludía a la tierra como aquella que comía cualquier carroña ${ }^{35}$.

Se hicieron otros muchos, pero me gustaría terminar con el gran mural que reproducía a tamaño original el Guernica de Picasso ${ }^{36}$, realizado un año des-

34 Sobre la década de los setenta Vid., Duarte, Galería Sur, Santander, septiembre de 1976; AA.VV., José Duarte, Obra Cultural de Caja de Ahorro de Córdoba, 1994 y Duarte, Diputación Provincial de Córdoba, Córdoba, 2002.

${ }^{35}$ Cortometraje de Esquivel, Humberto, op.cit.,

${ }^{36}$ En ese verano del 1975 se realizó otro mural más pequeño con una pintura de Picasso. 
pués por el equipo del pintor vasco Agustín Ibarrola. Bajo el título Guernica obra de Picasso exiliada en USA propiedad de los pueblos de España, supuso el punto y final de aquella aventura de Portugalete.

Fig. 17.

Programa de las fiestas del Barrio de Portugalete, 1976.

En aquellas fiestas de 1976 no sólo se pintó el Guernica sino que se celebró una feria de la artesanía (maderas, barro, alambre...), del grabado y del libro, gracias a los recién creados talleres del barrio de Arcadio Blasco y APSA ${ }^{37}$.

Todos aquellos stands de arte popular se cobijaron bajo los toldos proyectados por el arquitecto José Miguel Prada Poole ${ }^{38}$. Se trataba

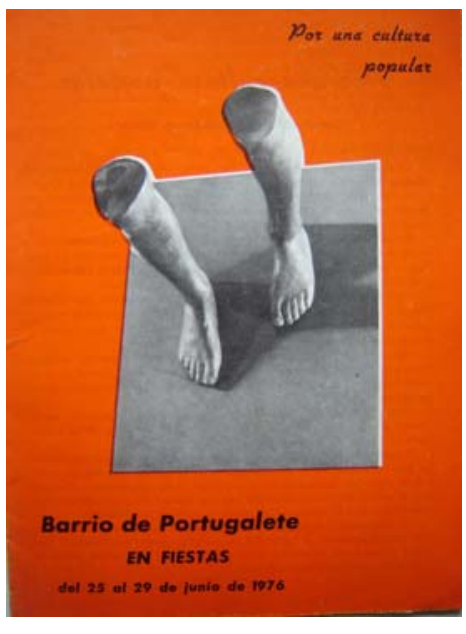
de una actividad muy especial, organizada por el Colegio de Arquitectos de Madrid bajo la designación de Montaje de hábitats de emergencia para la fiesta de arte popular ${ }^{39}$.

Sin duda, la referencia al Plan Parcial de Ordenación de la Ciudad Lineal seguía presente y más aún cuando se preveía la devastación total de un barrio:

Arrasamiento total del actual hábitat, abandonado por la administración con fines claramente favorecedores de la especulación. Expulsión de todos los vecinos actuales y ocupación del espacio por una minoría privilegiada ${ }^{40}$.

\footnotetext{
${ }^{37}$ Uno de aquellos talleres se funda en la Casa del Barrio, bajo la dirección de los artistas y considerado como la Primera Escuela de Arte para el Pueblo. En ella se impartieron clases de serigrafía, grabado a linóleum, telar, dibujo, pintura y cerámica. El taller se autofinanciaba gracias a la venta de las obras producidas.

${ }^{38}$ Anónimo, "Portugalete", Informaciones, Madrid, 1 de julio de 1976.

${ }^{39}$ Boletín de las fiestas, Por una cultura popular, Barrio de Portugalete en fiestas del 25 al 29 de junio de 1976, pág. 16.

${ }^{40}$ Ibíd., pág. 6
} 
Esta actividad puede relacionarse directamente con el XII Congreso Mundial de la Unión Internacional de Arquitectos (UIA) y su exposición de trabajos sobre "Habitat de emergencia" 41 y con la Conferencia de las Naciones Unidas sobre los Asentamientos Humanos, Informe de Hábitat, celebrada en Vancouver (Canadá) del 31 de mayo al 11 de junio de 1976 y en donde se planteó la necesidad de iniciar un programa de evacuación ante los desalojos forzosos.

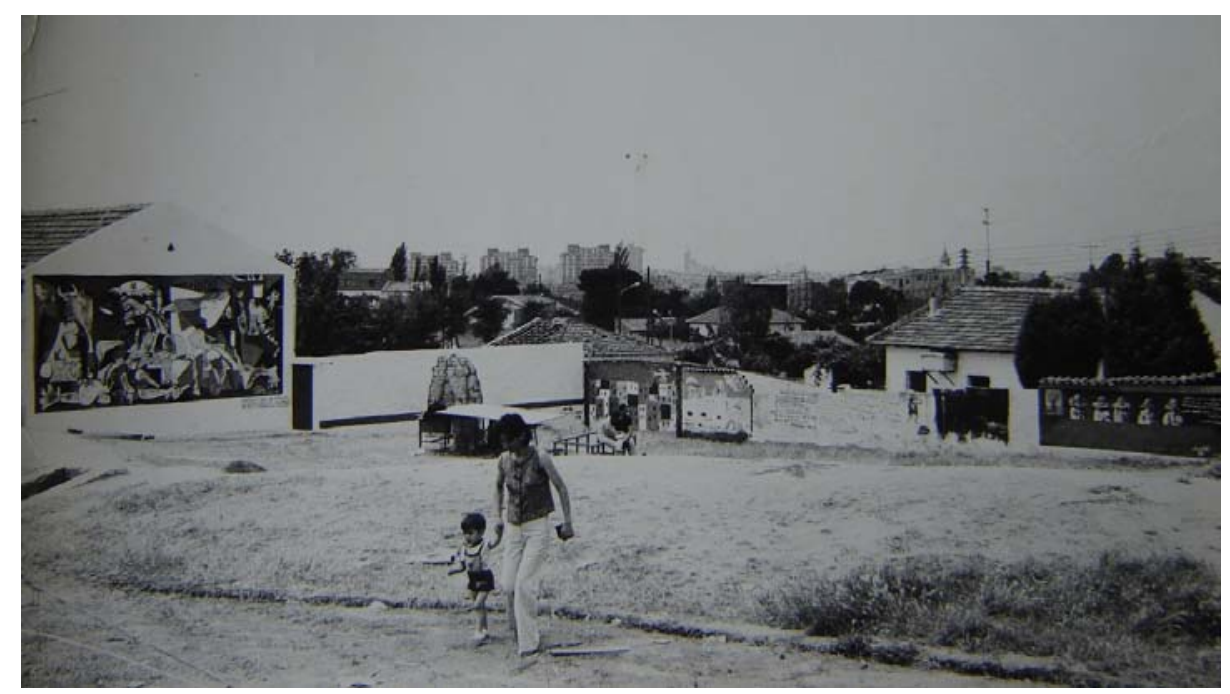

Fig. 18. Equipo de Agustín Ibarrola, El Guernica de Picasso.

Tanto los artistas plásticos a través de la AIAP (Asociación Internacional de Artistas Plásticos, Unesco) como los arquitectos estaban al corriente del desarrollo de la cultural exterior. En este sentido, cabría destacar que aquella enorme jaima, levantada por Prada Poole y titulada Mercadillo autoconstruible, estaba en consonancia con diversas construcciones de urbanismo efímero ${ }^{42}$. Y también con la Ciudad Instantánea de Prada, proyectada en el VII Congreso del ICSID (International Council of Societies of Industrial Design) del año 1972, destinada a alojar -en un campamento de arquitectura hinchable- a los

${ }^{41}$ Celebrado en Madrid durante el mes de mayo de 1975. Centro de Documentación y Biblioteca MNCARS, SIG. 875/3.

42 En este sentido cabe recordar las cúpulas neumáticas para los Encuentros de Pamplona de 1972. 
estudiantes sin dinero asistentes al congreso. Incluso próxima en su forma a Tela de Araña (1977), proyectada para la exposición Forma y Medida en el Arte español actual, celebrada en la salas de la Biblioteca Nacional de Madrid ${ }^{43}$.

En otro orden de cosas, igual que en la edición anterior, existió vigilancia policial incluso se llegaron a suspender aquellas fiestas por la Jefatura Superior de Policía al carecer del permiso de la Sociedad General de Autores para cualquier tipo de representaciones, como exigía el Sindicato del Espectáculo ${ }^{44}$.

$\mathrm{Al}$ igual que el año anterior el lema propuesto fue "Por una cultura popular":

La educación y la cultura 'se han puesto de moda'. El mundo del trabajo reivindica con más fuerza su derecho a la cultura. Hasta los sectores más recalcitrantes no pueden resistirse a los cambios culturales, que se avecinan y propugnan una 'popularización de la cultura'; es decir, una cultura 'rebajada', para uso y disfrute de la 'gente baja'.

La cultura es la llave de la libertad. Y es que hacer hombres libres y responsables no es otra cosa que poner las condiciones para que los hombres se cultiven, se desarrollen y alcancen a ser en la vida lo que la dignidad personal y comunitaria reclaman de cada ser humano.

Pero la verdadera cultura del pueblo oprimido es aquella que se forja con él y no para él. La construcción de una sociedad participada reclama también una vida cultura que permita a cada ciudadano sentirse miembro de la vida comunitaria en la que le ha tocado vivir...

Después del pan, la instrucción es la primera necesidad del pueblo'. Pero el ciudadano medio no participa en el libre juego cultural de la sociedad. No tiene acceso a las obras de arte y del espíritu; a la cultura universal, en definitiva.

Hemos de caminar hacia el desarrollo de la cultura popular, entendiendo ésta como el pueblo actuando como agente creador de su propia cultura y desarrollando sus propios valores.

Tradicionalmente la cultura ha cabalgado a lomos del individualismo, ya que cultivarse presuponía 'separarse de los demás', abstraerse y tratar de pasar por en-

${ }^{43}$ AA.VV., Derivas de la geometría. Razón y orden en la abstracción española, 1950-1975, Fundación Museo Jorge Oteiza, 2009.

${ }^{44}$ Anónimo, "Pintadas prohibidas en Portugalete", El País, Madrid, 27 de junio de 1976. 
cima de los otros, como en una competición. En cambio, el pueblo hoy siente el anhelo de una cultura de expresión comunitaria, en la que se reconozca su fuerte vivencia de la solidaridad... ${ }^{45}$.

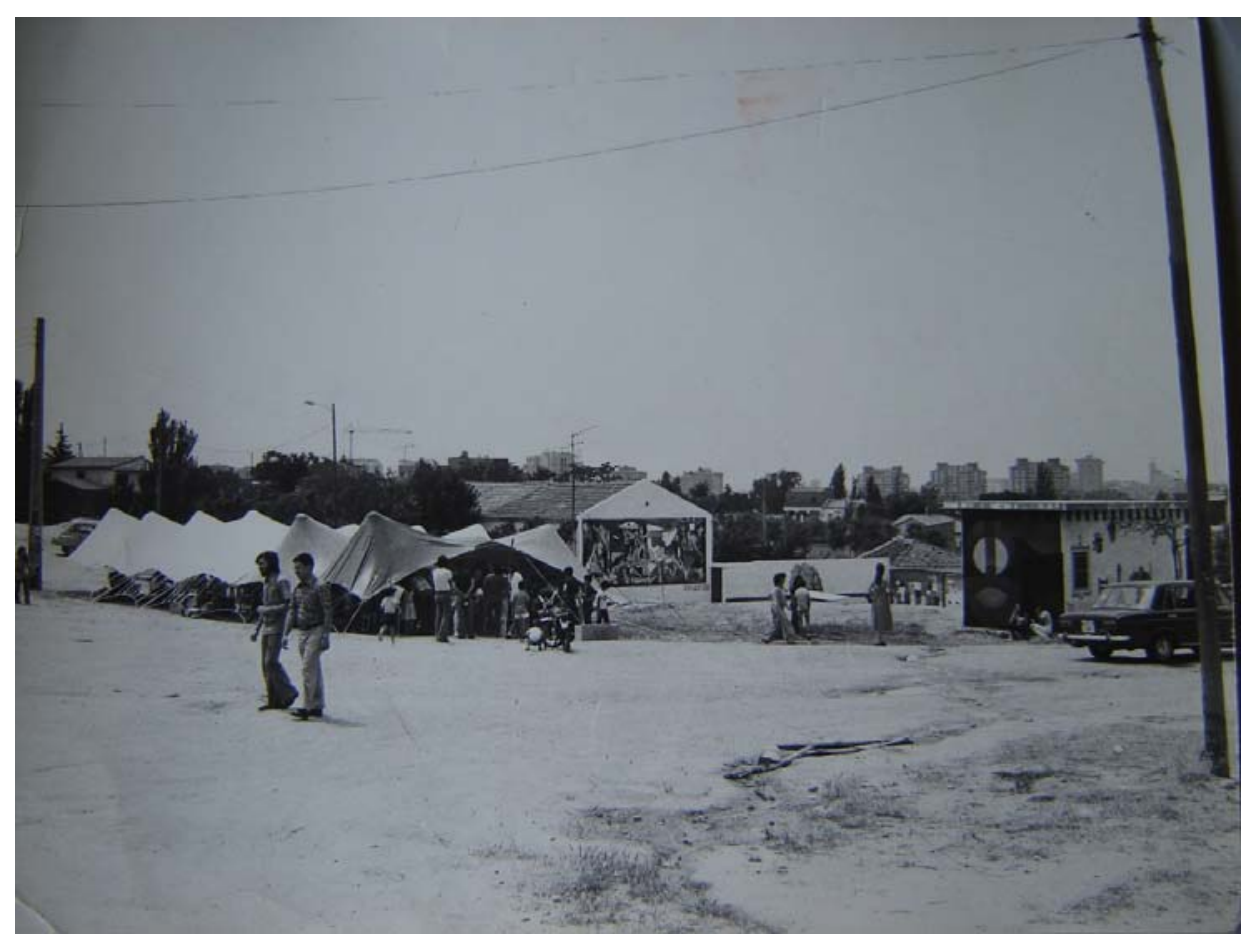

Fig. 19. José Manuel Prada Poole,

Montaje de hábitats de emergencia para la fiesta de arte popular Mercadillo autoconstruible

Los resultados de los murales fueron el precedente para nuevas intervenciones, aunque habría que resaltar el hecho de que, desde hacía varios años, se estaban realizando ya numerosas pintadas en barrios degradados de Barcelona, como en la Fábrica Tipel de Parets del Vallés" ${ }^{46}$ en Edificio Mallorca, en la Universidad de Bellaterra o en el barrio de San Juan de Pamplona ${ }^{47}$.

${ }^{45}$ Por una cultura popular, Barrio de Portugalete en fiestas del 25 al 29 de junio de 1976, op.cit., pp. 2 y 3. ${ }^{46}$ Fueron realizadas por los artistas Rafael Bartolozzi y Eduardo Arranz Bravo en 1968.

${ }^{47}$ Muñoz García, Pedro, “Los murales y la estética urbana”, op.cit., 
Entre otras intervenciones destaca la del 19 de noviembre de 1976, un año después de la muerte de Franco, en la Facultad de Económicas de Somosaguas $^{48}$ que, ante su cierre inmediato, fue cubierta con varios murales. Respaldada por una comisión de cultura de la Facultad y por un grupo de pintores de APSA, las pintadas fueron reivindicativas, contraculturales y de contenidos políticos. Se mantuvo la misma lucha por un arte libre: ya va siendo hora de sacar los cuadros de los museos, de convertir el arte en algo gratuito y cotidiano, no excepcional y para ricos. De desprivatizarlo. Y el lugar público, el de la expresión genuina en esta cultura urbana, es la pared. Y la calle ${ }^{49}$.

En otros barrios de Madrid como el Barrio del Pilar ${ }^{50}$, amenazados igualmente de expropiación, se realizaron otros murales, no sin consecuencias, ya que Juan Manuel Pera, Joaquin Cort y Gonzalo Torné miembros de APSA fueron detenidos. En ese mismo año se efectuaron en Alicante numerosos murales; por ejemplo, en la barriada de San Isidro, y con motivo de las fiestas patronales, se solicitaron crear 20 murales ${ }^{51}$; en Orihuela se celebró un homenaje de los Pueblos de España a Miguel Hernández con motivo del 35 Aniversario de su muerte, además de múltiples actividades en diferentes poblaciones de la provincia de Alicante ${ }^{52}$.

En mayo de 1976, una delegación de la APSA presentó en las ciudades de Lisboa y Bolonia las diapositivas de los trabajos realizados en Portugalete, Orihuela y Palomeras. También existió la idea de configurar una exposición con aquellas diapositivas en Estocolmo, asunto del que no tenemos más noticias ${ }^{53}$.

A pesar de todo, las dificultades en el barrio de Portugalete no terminaron $\mathrm{y}$, de hecho, continuaron siendo habituales en las reseñas periodísticas los

\footnotetext{
48 Pereda, Rosa María, “Aire libre en Somosaguas”, El País, Madrid, 19 de noviembre de 1976 y Anónimo, “Las 'pintadas' de Económicas”, El País, Madrid, 26 de noviembre de 1976.

${ }^{49}$ Pereda, Rosa María, “Aire libre en Somosaguas", op.cit.,

${ }^{50}$ Anónimo, “Detenidos veintitrés miembros del comité de Arte y seis de Cultura del PCE", El País, Madrid, 25 de marzo de 1977.

51 Archivo de la Democracia de la Universidad de Alicante, AD 017/016.

${ }^{52}$ Los actos tuvieron lugar entre el 17 y 27 de mayo de 1976. Algunos de aquellos murales como los de San Isidro en Orihuela han sido recuperados en marzo de 2011 por la Concejalía de Cultura. Vid., Archivo de la Democracia de la Universidad de Alicante, Sig. 017/001-012.

${ }^{53}$ Centro de Documentación y Biblioteca MNCARS, SIG. 875/14.
} 
problemas de su deterioro ${ }^{54}$. Al poco tiempo, se logró crear en marzo de 1976 la Casa del Barrio ${ }^{55}$ con el lema "Amigo, ésta es tu casa. Pasa, toma tu silla, siéntate. Podrás comprobar que hablando se entiende la gente". En febrero, la Junta Municipal procedió a mejorar la sección de alumbrado del barrio. Se logró colaborar en las normas de Participación Ciudadana del Ayuntamiento y fueron cofundadores de la Federación de Asociaciones de Vecinos. Y finalmente, se creó la cooperativa de viviendas "Portugalete", que permitió que en la revisión del Plan Parcial no fueran derribadas todas las casas y que se construyera un nuevo edificio para los vecinos más afectados por vivir en domicilios que no reunían las condiciones adecuadas.

\section{Bibliografía}

AA.VV. (2009): Derivas de la geometría. Razón y orden en la abstracción española, 1950-1975. Fundación Museo Jorge Oteiza.

AlBARRÁN DIEGO, Juan (2010): “Estéticas de la resistencia en el último franquismo: entre la investigación lingüística y la consolidación del movimiento asociativo". Artigrama, núm. 25, Zaragoza, 2010.

\footnotetext{
${ }^{54}$ Boletín informativo, Asociación de vecinos, Barrio de Portugalete, Madrid, enero de 1976; Martínez de Tejada, María José, "Manifestación con antorchas en el barrio de Portugalete", Informaciones, Madrid, 9 de febrero de 1976; Del Río, Ángel, “Los vecinos de Portugalete iluminaron su barrio con velas", Ya, Madrid, 10 de febrero de 1976; Anónimo, "Todo un barrio puede ser arrasado", El Alcázar, Madrid, 12 de febrero de 1976; Anónimo, “Asociación angustiosa para los vecinos del madrileña barrio de Portugalete", Blanco y Negro, Madrid, 21 de febrero de 1976; Castro Arines, José, "Portugalete", Informaciones, Madrid, 1 de julio de 1976; Anónimo, “En Madrid, Portugalete, patios del Abogado", Pueblo, Madrid, 11 de marzo de 1976; Anónimo, "El negocio de las chabolas", Ciudadano, Madrid, 15 de marzo de 1976; Velasco, "Barrio de Portugalete: todo son necesidades", Pueblo, Madrid, 6 de abril de 1976; Anónimo, "Anónimo, "Alquiler ilegal de chabolas en Portugalete", El País, Madrid, 30 de septiembre de 1977; Anónimo, "El barrio de Portugalete", Ya, Madrid, s.f; Anónimo, "El arte en la calle”, Arriba, Madrid, s.f.; Anónimo, "Veintidós propiedades inmobiliarias, afectadas por los ejes de núcleo 4 y 6", Ya, Madrid, s.f. y Boletín de la Asociación de vecinos, Barrio de Portugalete, Madrid, marzo de 1977, junio de 1978

55 Boletín de la Asociación de vecinos. Barrio de Portugalete, marzo de 1976 y Anónimo, "San Pascual: Nueva 'casa del barrio' en Portugalete", Ya, Madrid, 23 de marzo de 1976.
} 
ANÓNIMO (1972): “El área metropolitana aprueba”. ABC, Madrid, 26/10/1972.

_ (1973): ¿Qué va a ser de nuestro barrio? Unámonos. Asociación de vecinos Barrio de Portugalete, Madrid.

_ (1975): "En el barrio de Portugalete, artistas y vecinos llevan el arte a las tapias y paredes medianeras". Informaciones, 23 de junio de 1975.

_ (1975): "Los artistas del barrio". Triunfo, Madrid, 12 de julio de 1975

_ (1975): "Premios reseña 75". Doblón, Madrid, 12 de julio de 1975.

_ (1975): Boletín informativo, Asociación de vecinos, Barrio de Portugalete, núm.1, Madrid, febrero de 1975.

_ (1976): “Asociación angustiosa para los vecinos del madrileña barrio de Portugalete". Blanco y Negro, Madrid, 21 de febrero de 1976.

_ (1976): “El negocio de las chabolas". Ciudadano, Madrid, 15 marzo 1976.

_ (1976): "En Madrid, Portugalete, patios del Abogado". Pueblo, Madrid, 11 de marzo de 1976.

_ (1976): “Las 'pintadas' de Económicas”. El País, Madrid, 26 noviembre 1976.

_ (1976): “Pintadas prohibidas en Portugalete”. El País, Madrid, 27 junio de 1976.

_ (1976): "Portugalete". Informaciones, Madrid, 1 de julio de 1976.

_ (1976): "San Pascual: Nueva 'casa del barrio' en Portugalete". Ya, Madrid, 23 de marzo de 1976.

_ (1976): “Todo un barrio puede ser arrasado”. El Alcázar, Madrid, 12 de febrero de 1976.

_ (1976): Boletín de las fiestas, Por una cultura popular, Barrio de Portugalete en fiestas del 25 al 29 de junio de 1976, pág. 16.

_ (1976): Cuatro artistas alicantinos. Sala de exposiciones Alicante, enero-febrero de 1976.

_ (1977), “Detenidos veintitrés miembros del comité de Arte y seis de Cultura del PCE”. El País, Madrid, 25 de marzo de 1977.

_ (1977): “Alquiler ilegal de chabolas en Portugalete”. El País, Madrid, 30 de septiembre de 1977.

BALLESTER, José María (1975): “Arquitectura y urbanismo”. Blanco y negro, Madrid, 5 de julio de 1975.

CABEZAS (1976): "Mentidero de la villa. Fiestas y cultura popular en Portugalete", $A B C$, Madrid, 30 de junio de 1976.

CASTRO ARINES, José (1976): “Portugalete”. Informaciones, Madrid, 1 de julio 1976. 
De HARO GARCíA, Noemí (2010): Estampa Popular: Un arte crítico y social en la España de los años sesenta. Facultad de Geografía e Historia, Universidad Complutense, Madrid.

DE PRADO (1975): “Quieren formar sus juntas de compensación”. Arriba, Madrid, 10 de julio de 1975.

DEL Río, Ángel (1976): “Los vecinos de Portugalete iluminaron su barrio con velas", Ya. Madrid, 10 de febrero de 1976.

ESQUIVEL, Humberto (1976) Cortometraje: Por una cultura popular. Barrio de Portugalete en Fiestas, junio de 1976.

GIL MiNTXA (1975): “Arte en la calle para la calle”. Gaceta Ilustrada, julio de 1975.

MARTÍNEZ DE TEJADA, María José (1976): “Manifestación con antorchas en el barrio de Portugalete". Informaciones, Madrid, 9 de febrero de 1976.

Melero GinZO, Juan Antonio (1975): “Arte en la calle”. Gazeta del Arte, Madrid, 30 de septiembre de 1975.

MuÑOz GARCÍA (1975): “Los murales y la estética urbana”. Gazeta del Arte, 30 de septiembre de 1975.

NACHÓN, María Luz (1975): “Condiciones inhumanas en el barrio de Portugalete". Informaciones, Madrid, 13 de febrero de 1975.

PARREÑO, José María (2002): El arte comprometido en España en los años 70 y 80. Universidad Complutense, Madrid.

PeredA, Rosa María (1976): “Aire libre en Somosaguas". El País, Madrid, 19 de noviembre de 1976.

PRIETO BARRAL, María Fortunata (1975): “L'art dans la rue á Madrid”. Galerie jardins des arts, Paris, diciembre de 1975.

PYRESA (1975): “Una manifestación artística inédita”. Sur, 15 de julio 1975.

TRABAZO, Luis (1977): MNCARS. Material especial 6575.

VELASCO (1976): “Barrio de Portugalete: todo son necesidades”. Pueblo, Madrid, 6 de abril de 1976.

VIELBA, G. (1976): “El Barrio de Portugalete”. Boletín Informativo de la Real Sociedad Fotográfica, diciembre de 1976, pág. 17.

• historias-matritenses.blogspot.com.es/2011/04/barrio-de-portugalete-asociacion-de.html

- manuelrico.blogspot.com.es/2011/01/una-exposicion-que-enterro-el-urbanismo.html 